BRAVILLIAN JOURNAL

www.bjournal.com.br
ISSN 0100-879X

Volume 43 (4) 268-380 April 2011

BIOMEDICAL SCIENCES

AND

CLINICAL INVESTIGATION

Braz J Med Biol Res, April 2011, Volume 44(4) 297-302

doi: 10.1590/S0100-879X2011007500025

Expression and purification of the non-tagged LipL32 of pathogenic Leptospira

P. Hauk, E. Carvalho1 and P.L. Ho

The Brazilian Journal of Medical and Biological Research is partially financed by
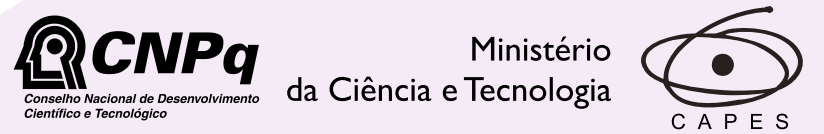

Ministério da Educação

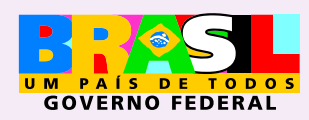

DTAPESP

Institutional Sponsors
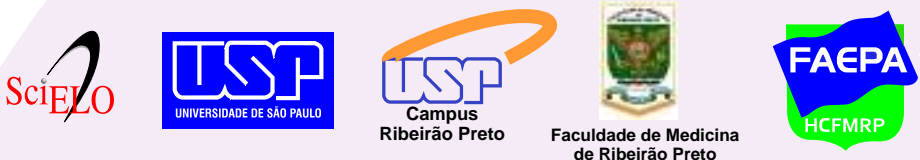

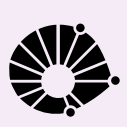

Ф SHIMADZU

GE Healthcare
Hotsite of proteomics metabolomics developped by:

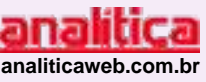




\title{
Expression and purification of the non-tagged LipL32 of pathogenic Leptospira
}

\author{
P. Hauk ${ }^{1,2}$, E. Carvalho ${ }^{1}$ and P.L. Ho ${ }^{1,2}$ \\ ${ }^{1}$ Centro de Biotecnologia, Instituto Butantan, São Paulo, SP, Brasil \\ 2Interunidades em Biotecnologia, Instituto de Ciências Biomédicas, Universidade de São Paulo,
} São Paulo, SP, Brasil

\begin{abstract}
Leptospirosis is a reemerging infectious disease and the most disseminated zoonosis worldwide. A leptospiral surface protein, LipL32, only occurs in pathogenic Leptospira, and is the most abundant protein on the bacterial surface, being described as an important factor in host immunogenic response and also in bacterial infection. We describe here an alternative and simple purification protocol for non-tagged recombinant LipL32. The recombinant LipL3221-272 was expressed in Escherichia coli without His-tag or any other tag used to facilitate recombinant protein purification. The recombinant protein was expressed in the soluble form, and the purification was based on ion exchange (anionic and cationic) and hydrophobic interactions. The final purification yielded $3 \mathrm{mg}$ soluble LipL3221-272 per liter of the induced culture. Antiserum produced against the recombinant protein was effective to detect native LipL32 from cell extracts of several Leptospira serovars. The purified recombinant LipL32 $21-272$ produced by this protocol can be used for structural, biochemical and functional studies and avoids the risk of possible interactions and interferences of the tags commonly used as well as the time consuming and almost always inefficient methods to cleave these tags when a tag-free LipL32 is needed. Non-tagged LipL32 may represent an alternative antigen for biochemical studies, for serodiagnosis and for the development of a vaccine against leptospirosis.
\end{abstract}

Key words: Antigen; LipL32; Pathogenic Leptospira; Non-tagged protein purification; Diagnosis; Vaccine

\section{Introduction}

Leptospirosis is a zoonosis caused by the genus Leptospira. Humans and domestic animals are most commonly infected through contact with the urine of carrier animals, either directly or via contaminated water or soil. In humans, this disease is characterized by fever, renal and hepatic insufficiency and pulmonary manifestations (1). The most abundant antigen found in the leptospiral total protein profile is LipL32, displaying around 40,000 copies/cell (2). This lipoprotein is highly conserved among pathogenic Leptospira species (3), but no orthologs were observed in the saprophytic non-pathogenic Leptospira biflexa (4). Expressed at high levels both during cultivation and natural infection, LipL32 was shown to be surface exposed and highly immunogenic (3). This lipoprotein is also involved in the pathogenesis of tubulointerstitial nephritis that is the main renal manifestation. Pathogenic leptospires accumulate mostly in the proximal tubules and induce the expression of inflammatory molecules, part of this response being mediated by LipL32 (5). Considering these remarkable findings, many strategies have used LipL32 as a target for vaccine development and diagnosis (for a review, see Ref. 6). Studies performed with the $\mathrm{C}$-terminal and intermediate domains of LipL32 have shown that they are recognized by sera of patients. For instance, an IgM response was detected exclusively against the LipL32 C-terminus in both the acute and convalescent phases of illness (7). Moreover, the capacity of LipL32 to interact with extracellular matrix components such as laminin (8), collagen type IV and plasma fibronectin (7) was also described. A dosedependent and specific binding of LipL32 to collagen IV and plasma fibronectin was observed, and interestingly, the binding capacity could be attributed to the C-terminal portion of this molecule. Both heparin and gelatin could inhibit LipL32 binding to fibronectin in a concentration-dependent manner, indicating that the $30-\mathrm{kDa}$ heparin- and the $45-$ $\mathrm{kDa}$ gelatin-binding domains of fibronectin are involved in this interaction $(7,8)$. Surprisingly, studies using the lipL32 mutant have shown that it does not play a role in either

Correspondence: P.L. Ho, Centro de Biotecnologia, Instituto Butantan, Av. Vital Brasil, 1500, 05503-900 São Paulo, SP, Brasil.

Fax: +55-11-3726-1505. E-mail: hoplee@butantan.gov.br

Received November 7, 2010. Accepted February 16, 2011. Available online March 4, 2011. Published April 11, 2011. 
the acute or chronic models of infection (9). While these data do not suggest a role in pathogenesis, a function for LipL32 has not been demonstrated. In the present study, we describe the cloning and purification of LipL3221-272 (LipL32 containing amino acids 21 to 272) without His-tag or any other tag commonly used to facilitate recombinant protein purification.

\section{Material and Methods}

Bacterial strains, plasmids, and culture conditions

Leptospiral strains were obtained from the Faculdade de Medicina Veterinária e Zootecnia, Universidade de São Paulo (USP), Brazil. E. coli DH5a was used as the cloning host strain and E. coli BL21 (SI) (Gibco/BRL, USA) as the host strain for efficient overproduction of cloned gene products using $\mathrm{NaCl}$ as the inducer (10). Recombinant $E$. coli BL21 (SI) cells were grown on 2YT ON (16 g/L tryptone and $10 \mathrm{~g} / \mathrm{L}$ yeast extract) medium supplemented with ampicillin $(100 \mu \mathrm{g} / \mathrm{mL})$ before induction.

\section{Cloning steps and screening of the recombinant plasmids}

To avoid misfolding and aggregation of the recombinant protein, the region coding for the hydrophobic signal peptide (amino acids 1 to 20) was not included in the cloned fragment. PCR was used to amplify the gene fragment coding for LipL32 $21-272$ using a genomic DNA purified from L. interrogans serovar Copenhageni strain Fiocruz L1-130 isolated from a patient in Salvador, Brazil (ATCC No. BAA1198) (11), as template, with the forward primer (5'-CTC GAGCATATGGGTGCTTTCGGTGGTCTG-3') containing $X$ hol and Ndel restriction endonuclease sites (underlined) and the reverse primer (5'-AAGCTTACTTAGTCGCGT CAGAAGC-3') containing a HindIII (underlined) restriction site. Plasmid pGEM-T easy (Promega, USA) was used to clone the amplified gene. The resulting 759-bp fragment was cloned into $\mathrm{Ndel} / \mathrm{Hind}$ III sites in the T7 promoter-based expression plasmid pAE (12). E. coli DH5a competent cells were transformed with the ligation product. Recombinant colonies were analyzed by a protocol based on the size of the plasmid (13). Positive clones were investigated for the presence of the correct insert by DNA sequencing.

\section{Expression in E. coli}

E. coli BL21 (SI) competent cells (Gibco/BRL) were transformed with the pAE-lipL32 and grown overnight at $30^{\circ} \mathrm{C}$. In this strain, the expression of T7 RNA polymerase is under the control of the $E$. coliosmotically inducible promoter proU (10). The transformed E. coli BL21 (SI) was cultured in $1 \mathrm{~L} 2$ YT ON medium containing ampicillin and grown until the optical density reached 0.6 at $600 \mathrm{~nm}$. The expression of the recombinant protein was induced with $0.3 \mathrm{M} \mathrm{NaCl}$, followed by culture for an additional $3 \mathrm{~h}$ at $30^{\circ} \mathrm{C}$. The cells were collected by centrifugation and resuspended in 100
$\mathrm{mL} 20 \mathrm{mM}$ triethanolamine, $\mathrm{pH} 7.8$, and lysed in a French press (Thermo Spectronic, USA) at 30,000 psi. The soluble and insoluble fractions were isolated by centrifugation at $8400 \mathrm{~g}$ for $10 \mathrm{~min}$.

\section{Purification of the recombinant LipL3221-272}

The soluble fraction recovered from the centrifugation step described above was applied to a column $(1 \mathrm{~cm}$ in diameter) containing $5 \mathrm{~mL}$ Q-Sepharose Fast Flow resin (GE HealthCare, USA) previously equilibrated with $20 \mathrm{mM}$ triethanolamine, $\mathrm{pH}$ 7.8. The unbound fraction containing LipL32 21-272 was harvested and then applied to a column of similar dimension containing SP-Sepharose Fast Flow resin (GE Healthcare). After adsorption of LipL3221-272 protein to the cationic resin, the preparation was washed with 10 column volumes of $20 \mathrm{mM}$ triethanolamine, $\mathrm{pH} 7.8$, containing $0.1,0.3,0.5,0.7,1.0,1.5$, and $2.0 \mathrm{M} \mathrm{NaCl}$, respectively. Fractions were analyzed by $15 \%$ SDS-PAGE to detect the presence of LipL3221-272. Samples containing LipL3221-272 were pooled, $\mathrm{NaCl}$ was added to a final concentration of 3.0 $\mathrm{M}$ and this mixture was then adsorbed to a PhenylSepharose Fast Flow column (GE HealthCare) previously equilibrated with $20 \mathrm{mM}$ triethanolamine, $\mathrm{pH} 7.8$, and 3.0 $\mathrm{M} \mathrm{NaCl}$. After the adsorption of the recombinant protein, the resin was washed with 10 column volumes of $20 \mathrm{mM}$ triethanolamine, $\mathrm{pH} 7.8$, containing $2.5,2.0,1.5,1.0,0.7$, $0.5,0.3$, and $0.1 \mathrm{M} \mathrm{NaCl}$, respectively, and finally, $20 \mathrm{mM}$ triethanolamine, $\mathrm{pH} 7.8$, and $\mathrm{H}_{2} \mathrm{O}$. The chromatographic steps were carried out with a peristaltic pump (P-1, GE HealthCare). The eluted fractions were analyzed by $15 \%$ SDS-PAGE. Proteins were pooled from selected fractions, dialyzed with three changes, each consisting of $2 \mathrm{~L} 20 \mathrm{mM}$ triethanolamine, $\mathrm{pH} 7.8$, every $18 \mathrm{~h}$, and considered to be the final LipL3221-272 preparation.

\section{Production of LipL3221-272 antiserum}

Five- to eight-week-old female BALB/c mice were immunized intraperitoneally with $10 \mu \mathrm{g}$ purified LipL32 $21-272$ and $100 \mu \mathrm{g}$ aluminum ion (added in the form of $\left.\mathrm{Al}(\mathrm{OH})_{3}\right)$. The immunizations were performed over a period of 4 weeks, with booster doses at every week. Mice were bled by the retrorbital plexus and blood was incubated for $30 \mathrm{~min}$ at $37^{\circ} \mathrm{C}$. The clot was then removed by centrifugation and the serum was collected from the supernatant.

\section{Western blot}

Leptospira extracts were fractionated by $15 \%$ SDSPAGE and electro-transferred to a nitrocellulose membrane. The membrane was incubated with $10 \%(\mathrm{w} / \mathrm{v})$ non-fat dried milk in $0.05 \%$ Tween 20/phosphate-buffered saline (PBS$\mathrm{T})$ and after three washes with PBS-T for $10 \mathrm{~min}$, it was further incubated with mouse anti-recombinant LipL3221-272 serum in 5\% non-fat dried milk-PBS-T for $1 \mathrm{~h}$. Following the repetition of the PBS-T wash as described above, the membrane was incubated with a proper dilution of goat 
anti-mouse IgG peroxidase conjugate (Sigma) in 5\% nonfat dried milk-PBS-T, washed, and developed with ECL reagent (GE HealthCare).

\section{Results}

Cloning, expression and purification of recombinant LipL3221-272

The gene fragment coding for LipL3221-272 $(3,14)$ was amplified by PCR and cloned in the $E$. coli expression vector pAE (12). The resulting plasmid pAE-lipL32 codes for the expression of LipL32 $21-272$ with an additional Met at the Nterminus of the molecule (we will refer to this molecule as LipL32 21-272). Recombinant LipL32 21-272 was expressed in E. coli BL21 (SI) after induction by $0.3 \mathrm{M} \mathrm{NaCl}$. The protein was expressed both in the soluble and in the insoluble fractions (data not shown). We found equal levels of LipL32 $21-272$ in the inclusion bodies and in the soluble fraction. We preferred to purify LipL32 $21-272$ from the soluble fraction, since this material is likely to be in the native and correct conformation. The soluble LipL3221-272 was purified in three chromatographic steps (Figure 1A). In the first step, the soluble fraction was adsorbed onto a Q-Sepharose column. The flow through containing LipL3221-272 (Figure $1 \mathrm{~B}$ ) was further purified by SP-Sepharose and the protein eluted in $0.1 \mathrm{M} \mathrm{NaCl}, 20 \mathrm{mM}$ triethanolamine, $\mathrm{pH}$ 7.8 (fraction $\mathrm{P} 1$, Figure $1 \mathrm{~B}$ ). In the third step, the sample containing LipL3221-272 eluted from the cationic chromatography was adjusted to $3 \mathrm{M} \mathrm{NaCl}$ and finally purified by Phenyl-Sepharose (fraction P2, Figure 1C). The recombinant LipL32 $21-272$ was eluted in $0.5,0.3,0.1 \mathrm{M} \mathrm{NaCl}$ in 20 $\mathrm{mM}$ triethanolamine, $\mathrm{pH} 7.8$, and $20 \mathrm{mM}$ triethanolamine, $\mathrm{pH} 7.8$, and $\mathrm{H}_{2} \mathrm{O}$. The samples enriched with LipL3221-272 were those eluted with $0.5,0.3$, and $0.1 \mathrm{M} \mathrm{NaCl}$ (fraction $\mathrm{P} 2$, Figure 1C). These fractions were dialyzed in three steps with $2 \mathrm{~L} 20 \mathrm{mM}$ triethanolamine, $\mathrm{pH} 7.8$, and concentrated to $10 \mathrm{~mL}$ using an Amicon ultrafiltration system with a 10-kDa cut-off membrane (Figure 1D). The final purification yield considering fraction P2 was approximately $3 \mathrm{mg} / \mathrm{L}$ culture

Table 1. Purification yield of LipL3221-272.

\begin{tabular}{lccc}
\hline Sample & $\begin{array}{c}\text { Recovery } \\
\text { (LipL32, mg/L) }\end{array}$ & $\begin{array}{c}\text { Yield } \\
(\% \text { LipL32) }\end{array}$ & $\begin{array}{c}\text { Homogeneity } \\
(\%)\end{array}$ \\
\hline Crude extract & 35 & 100 & 30 \\
Flow through (Q-Sepharose) & 30 & 85 & 42 \\
P1 (S-Sepharose) & 25 & 71 & 47 \\
P2 (Phenyl-Sepharose) & 3 & 8 & 98 \\
\hline
\end{tabular}

The relative amount of LipL3221-272 in the fractions was estimated from densitometric analysis of the SDS-PAGE gels shown in Figure $1 \mathrm{~B}$ and C. LipL32 21-272 recovery was determined by submitting known quantities of bovine serum albumin to SDS-PAGE gels followed by densitometric analysis. Homogeneity was determined by SDS-PAGE. The data reported are the results of one representative preparation. and more than $95 \%$ pure (Table 1 ), suitable for crystallographic and tertiary structural studies $(15,16)$.

\section{Production of LipL32121-272 antiserum}

The purified LipL32 21-272 was inoculated in female BALB/c mice for the production of antiserum against LipL32. The antiserum obtained was able to recognize the recombinant LipL3221-272 in Western blot (Figure 1E, lane 11). Moreover, a conserved 32-kDa band corresponding to the expected size of LipL32 was also recognized in the extracts of a large panel of pathogenic Leptospira (L. interrogans serovars Canicola, Pyrogenes, Pomona, Autumnalis, Hardjo, Brastilava, Copenhageni, and Icterohaemorrhagiae, and $L$. kirschneri serovar Grippotyphosa), whereas no reaction was observed in the extract of the non-pathogenic saprophytic L. biflexa serovar Patoc (Figure 1E).

\section{Discussion}

Affinity tags are efficient tools for protein purification since they facilitate the derivation of large amounts of highly homogenous proteins from heterologous expression systems (17). His-tags are the most widely used affinity tags, but several others are also widely used such as the maltose-binding protein, glutathione-S-transferase, chitinbinding domain, and elastin-like polypeptide tag. His-tag binding to metal is not affected by urea solutions used to solubilize proteins expressed in inclusion bodies in contrast to the other tags that require non-denaturing conditions to be functional. Affinity tags may have a positive or negative effect on the biochemical properties of the target protein (17). Examples of positive effects are protein yield improvement, protein refolding facilitation, proteolysis prevention, preservation of fusion protein antigenicity, and increased solubility. Most of the negative effects are related to changes in protein conformation, lower protein yields, inhibition of enzyme activity, alteration of biological activity, undesired flexibility in structural analysis, and toxicity (17). Due to unpredictable changes that adding a tag would introduce in a protein, we obtained LipL32 $21-272$ without any tags. The purification of LipL32 $21-272$ was based on ion exchange (both anionic and cationic) and hydrophobic interaction chromatography. For structural studies, an additional concentration step is necessary. LipL32 is considered to be an important antigen in leptospirosis $(3,16,18)$. It is highly immunogenic and expressed on the surface of pathogenic Leptospira sp $(2,3,7,8)$. However, the exact biological role of this protein in leptospirosis or in Leptospira biology is unknown. Since LipL32 is well conserved in all pathogenic species tested to date, but absent in free-living $L$. biflexa serovar Patoc $(3,4)$ (Figure 1E), it was suggested that LipL32 could be involved in leptospiral pathogenicity. However, an L. interrogans mutant 
A

E. coli BL21 (SI)

Lysis

Supernatant (S)<smiles>C=[V]</smiles>

Q-sepharose (Q)

Flow Through (FT)

SP-sepharose (SP)

$0.1 \mathrm{M} \mathrm{NaCl}(\mathrm{P} 1)$

Phenyl sepharose

0.5- $0.1 \mathrm{M} \mathrm{NaCl}(\mathrm{P} 2)$

LipL32 $21-272$

D

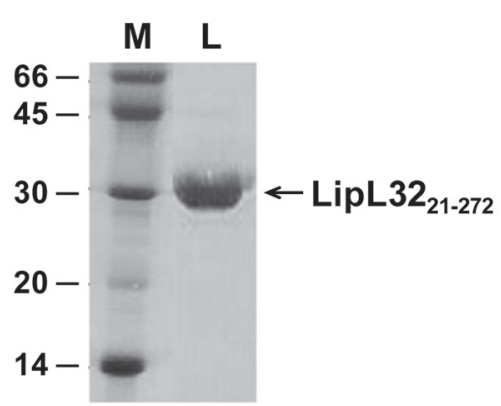

B

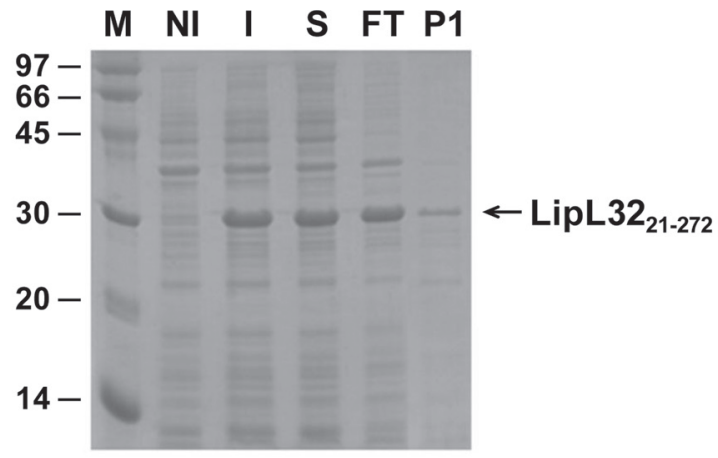

P2

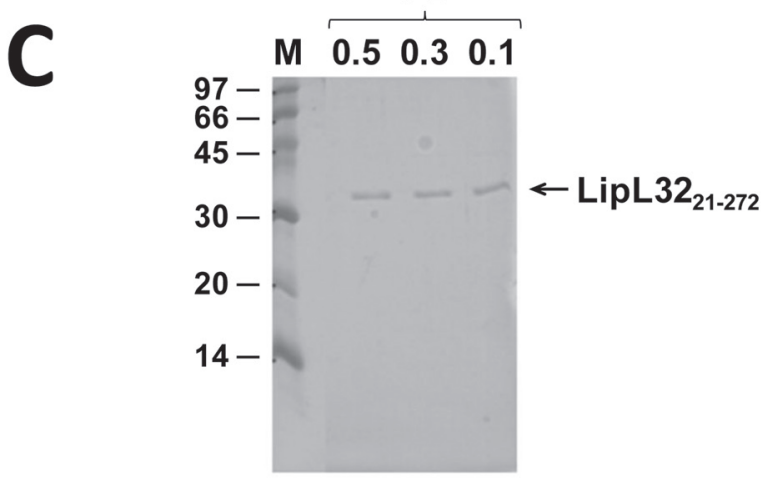

E

$\begin{array}{lllllllllll}1 & 2 & 3 & 4 & 5 & 6 & 7 & 8 & 9 & 10 & 11\end{array}$

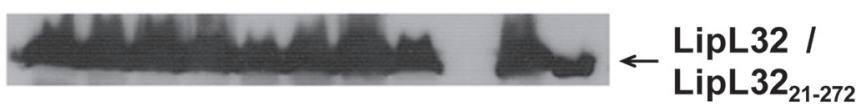

Figure 1. Expression and purification of LipL32 $21-272$ and antiserum recognition of native LipL32. Panel A, Flowchart showing the three main steps of LipL3221-272 purification. SI = Escherichia coli BL21; $\mathrm{S}=$ supernatant; $\mathrm{Q}=$ anion exchange; $\mathrm{FT}=$ flow through unbound proteins; $\mathrm{SP}=$ cation exchange; $\mathrm{P} 1=0.1 \mathrm{M} \mathrm{NaCl}$ - fraction containing LipL3221-272 eluted with $0.1 \mathrm{M} \mathrm{NaCl} ; \mathrm{P} 2=$ purified LipL32 21-272. Panel B, SDS-PAGE of LipL3221-272 purification shown in Panel A. M = Molecular marker; $\mathrm{NI}=$ non-induced E. coli $\mathrm{BL} 21$ (SI); I = E. coli BL21 (SI) induced with NaCl; $\mathrm{S}=$ supernatant; $\mathrm{FT}=$ flow through - unbound proteins; $\mathrm{P} 1=0.1 \mathrm{M} \mathrm{NaCl}-$ fraction containing LipL32 21-272 eluted with 0.1 M NaCl. Panel C, SDS-PAGE of LipL3221-272 purified from Phenyl-Sepharose. M = Molecular marker; P2 = purified LipL32 21-272 after elution with $0.5,0.3$, and $0.1 \mathrm{M} \mathrm{NaCl}$ using Phenyl-Sepharose. Panel D, SDS-PAGE showing the purified LipL3221-272. M = Molecular marker; $L=$ LipL3221-272 after membrane concentration (cut off $10 \mathrm{kDa}$ ). Panel E, Western-blot showing that anti-non-tagged LipL3221-272 antiserum recognizes native LipL32 from cell extracts of different Leptospira serovars. Lane 1, Whole-cell extracts of L. interrogans serovars Icterohaemorrhagiae; lane 2, Copenhageni; lane 3, Bratislava; lane 4, Hardjo; lane 5, Autumnalis; lane 6, Pomona; lane 7, Pyrogenes; lane 8, Canicola, and lane 10, L. kirschneri serovar Grippotyphosa. Serum also recognized the recombinant protein (lane 11) but failed to react with the whole-cell extract of non-pathogenic L. biflexa serovar Patoc (lane 9). 
lacking functional LipL32 did not show any detectable loss in the ability to infect and colonize hosts or even to survive in water, making this a paradoxical protein (9).

Structural studies have shown a tertiary structure related to jelly roll fold proteins $(16,18)$. Indeed, in both structural studies, LipL32 was crystallized without His-tag. In the first attempt to crystallize LipL32, the protein was obtained with a His-tag that was further cleaved out using the V8 staphylococcus protease. The removal of the His-tag was necessary to obtain suitable LipL32 for high-quality structural studies. The purification method used by Vivian et al. (18) included several steps: Nickel-Sepharose followed by gel-filtration chromatography (S75 16/60), a Mono Q50/50 anion-exchange column and the unbound fraction containing pure LipL32 was proteolyzed to the V8 protease and finally reapplied to the S75 $16 / 60$ column. However, problems may be encountered during the cleavage step, including low yield, precipitation of the target protein, tedious optimization of cleavage conditions, high cost of proteases or failure to recover the active or structurally intact protein (19). In addition, some biochemical features of LipL32 may be better explored using a non-tagged protein to avoid possible interferences. We proposed here a simple

\section{References}

1. Adler B, de la Pena MA. Leptospira and leptospirosis. Vet Microbiol 2010; 140: 287-296.

2. Malmstrom J, Beck M, Schmidt A, Lange V, Deutsch EW, Aebersold R. Proteome-wide cellular protein concentrations of the human pathogen Leptospira interrogans. Nature 2009; 460: 762-765.

3. Haake DA, Chao G, Zuerner RL, Barnett JK, Barnett D, Mazel $\mathrm{M}$, et al. The leptospiral major outer membrane protein LipL32 is a lipoprotein expressed during mammalian infection. Infect Immun 2000; 68: 2276-2285.

4. Picardeau M, Bulach DM, Bouchier C, Zuerner RL, Zidane $\mathrm{N}$, Wilson PJ, et al. Genome sequence of the saprophyte Leptospira biflexa provides insights into the evolution of Leptospira and the pathogenesis of leptospirosis. PLoS One 2008; 3: e1607.

5. Yang CW, Wu MS, Pan MJ, Hsieh WJ, Vandewalle A, Huang CC. The Leptospira outer membrane protein LipL32 induces tubulointerstitial nephritis-mediated gene expression in mouse proximal tubule cells. J Am Soc Nephrol 2002; 13: 2037-2045.

6. Palaniappan RU, Ramanujam S, Chang YF. Leptospirosis: pathogenesis, immunity, and diagnosis. Curr Opin Infect Dis 2007; 20: 284-292.

7. Hauk P, Macedo F, Romero EC, Vasconcellos SA, de Morais $Z M$, Barbosa AS, et al. In LipL32, the major leptospiral lipoprotein, the $C$ terminus is the primary immunogenic domain and mediates interaction with collagen IV and plasma fibronectin. Infect Immun 2008; 76: 2642-2650.

8. Hoke DE, Egan S, Cullen PA, Adler B. LipL32 is an extracellular matrix-interacting protein of Leptospira spp and Pseudoalteromonas tunicata. Infect Immun 2008; 76: 2063-2069. method to purify homogenous non-tagged LipL32. A partial but not detailed description of this protocol has been published $(15,16)$. Studies performed by our group using this non-tagged LipL32 purified by ion exchange (anionic and cationic) and hydrophobic interactions showed that LipL32 binds to calcium in a specific manner but not to zinc or copper ions. This kind of study would not be possible with a His-tagged LipL32. Besides, the purified non-tagged LipL32 yielded high-quality crystals suitable for diffraction data and three-dimensional structure determination (16) and may also represent an alternative antigen for serodiagnosis and vaccine development for leptospirosis, although His-tagged LipL32 have proved so far to be highly immunogenic as well (20). Overall, we believe that a description of a method for obtaining purified non-tagged LipL32 may be useful for researchers in the field, since this is the most abundant protein on the leptospiral surface.

\section{Acknowledgments}

Research supported by FAPESP, CNPq, and Fundação Butantan.
9. Murray GL, Srikram A, Hoke DE, Wunder EA Jr, Henry R, Lo M, et al. Major surface protein LipL32 is not required for either acute or chronic infection with Leptospira interrogans. Infect Immun 2009; 77: 952-958.

10. Bhandari P, Gowrishankar J. An Escherichia coli host strain useful for efficient overproduction of cloned gene products with $\mathrm{NaCl}$ as the inducer. J Bacteriol 1997; 179: 44034406.

11. Nascimento AL, Verjovski-Almeida $S$, Van Sluys MA, Monteiro-Vitorello CB, Camargo LE, Digiampietri LA, et al. Genome features of Leptospira interrogans serovar Copenhageni. Braz J Med Biol Res 2004; 37: 459-477.

12. Ramos CR, Abreu PA, Nascimento AL, Ho PL. A high-copy T7 Escherichia coli expression vector for the production of recombinant proteins with a minimal $\mathrm{N}$-terminal His-tagged fusion peptide. Braz J Med Biol Res 2004; 37: 1103-1109.

13. Beuken E, Vink C, Bruggeman CA. One-step procedure for screening recombinant plasmids by size. Biotechniques 1998; 24: 748-750.

14. Lee SH, Kim KA, Park YG, Seong IW, Kim MJ, Lee YJ. Identification and partial characterization of a novel hemolysin from Leptospira interrogans serovar lai. Gene 2000; 254: 19-28.

15. Hauk P, Guzzo CR, Ho PL, Farah CS. Crystallization and preliminary X-ray analysis of LipL32 from Leptospira interrogans serovar Copenhageni. Acta Crystallogr Sect F Struct Biol Cryst Commun 2009; 65: 307-309.

16. Hauk P, Guzzo CR, Roman RH, Ho PL, Farah CS. Structure and calcium-binding activity of LipL32, the major surface antigen of pathogenic Leptospira sp. J Mol Biol 2009; 390: 722-736. 
17. Arnau J, Lauritzen C, Petersen GE, Pedersen J. Current strategies for the use of affinity tags and tag removal for the purification of recombinant proteins. Protein Expr Purif 2006; 48: 1-13.

18. Vivian JP, Beddoe T, McAlister AD, Wilce MC, Zaker-Tabrizi L, Troy S, et al. Crystal structure of LipL32, the most abundant surface protein of pathogenic Leptospira spp. J Mol Biol 2009; 387: 1229-1238.
19. Baneyx F, Mujacic M. Recombinant protein folding and misfolding in Escherichia coli. Nat Biotechnol 2004; 22: 1399-1408.

20. Luo D, Xue F, Ojcius DM, Zhao J, Mao Y, Li L, et al. Protein typing of major outer membrane lipoproteins from Chinese pathogenic Leptospira spp. and characterization of their immunogenicity. Vaccine 2009; 28: 243-255. 